\title{
The Wave Heights Distribution of Random Wave Based on Ocean Basin
}

\author{
Nurman Firdaus $\left.{ }^{1)^{*}}\right)$, Baharuddin Ali $^{2)}$, Mochammad Nasir ${ }^{2)}$, Muryadin ${ }^{2)}$ \\ 1)Department of Ocean Engineering, Institut Teknologi Sepuluh Nopember, Surabaya 60111, Indonesia \\ 2) Indonesian Hydrodynamics Laboratory, Center for Hydrodynamics Technology, Agency for the Assessment and Application of \\ Technology (BPPT), Surabaya 60112, Indonesia \\ *) Corresponding Author : firdaus.norman.oe@gmail.com
}

Article Info

Abstract

\section{Keywords:}

Ocean wave, sea state, wave height wave spectrum, probability distribution

\section{Article history:}

Received: 19/06/20

Last revised: 08/09/20

Accepted: 01/10/20

Available online: 31/10/20

DOI:

https://doi.org/10.14710/kapal. v17i3.31021
The wave height parameter in ocean waves is one of the important information for a marine structure design. The present paper investigates the results of wave heights distribution from laboratorygenerated for single sea state. Data of the random wave time series collected at the ocean basin are analyzed using the wave spectrum and compared with the theoretical spectrum in this study. The random wave data is varied with four sea states consisting of sea states 3, 4, 5 and 6 obtained from laboratory measurements. The parameter conditions of generated sea waves are represented by a value of significant wave height and wave peak period in the range of sea states. The individual wave heights data in each sea state are presented in the form of exceedance probability distribution and the predictions using a linear model. This study aims to estimate the wave heights distribution using the Rayleigh and Weibull distribution model. Furthermore, the accuracy of the wave heights distribution data's prediction results in each sea state has been compared and examined for both models. The applied linear models indicate similar and reasonable estimations on the observed data trends.

Copyright (C) 2020 KAPAL : Jurnal Ilmu Pengetahuan dan Teknologi Kelautan. This is an open access article under the CC BY-SA license (https://creativecommons.org/licenses/by-sa/4.0/).

\section{Introduction}

Ocean waves are one of the parameters that affect the calculation of wave load and coastal and offshore structures' response. The wave heights or crest-to-trough waves generated within random waves should be considered for the marine structure's design, as the maximum wave height can have a significant effect on the lifetime of these structures. The statistical analysis of wave heights is vital for the design of marine structures [1]. Therefore, the knowledge of statistical models explaining the wave heights distribution is an essential requirement for the design process of various ocean structures. The wave height distribution can represent a key input for designing the structure in ocean engineering [2].

The estimation of the wave height distribution can apply some widely used models by scientific and engineering practices. Various theoretical models have been developed to characterize the probability distribution of wave heights. Prevosto et al. [3] studied the probability distribution models of short-term and long-term to estimate ocean waves' maximum wave height. Guedes Soares and Pascoal [4] conducted a study on the application of several distribution models to predict the wave height distribution used to know a phenomenon related to green water loading.

Cherneva et al. [5] performed a study of the probability distribution model of considerable wave heights derived from sea surface elevation measurements. Tuan \& Cuong [6] performed a study of the wave heights distribution to investigate wave heights' statistical characteristics on steep submerged (platform) reefs. Karmpadakis et al. [7] investigated the shortterm statistical distribution of wave heights that are evaluated using field measurements in intermediate and shallow water depths.

According to a linear wave theory, the wave spot at a fixed point is assumed to be Gaussian sea because the ocean wave is be learned as random processes. In the case of a Gaussian sea and a single sea state, the Rayleigh distribution is referred to as a model for distributing wave height with a narrowband spectrum [8]. The additional assumption is similar to the linear wave analysis. The wave height is also taken twice the wave amplitude as the Rayleigh distribution is applicable to wave heights [9].

The Rayleigh distribution can describe the wave height dan the statistical relationship of the wave parameter exactly. Nevertheless, there are some discrepancies with the measurement data in ocean engineering design [10], [11], [12]. Because in fact, the real wave is affected by the nonlinear wave interactions between spectral wave components. Although the 
Rayleigh distribution model differs slightly with the data in some instances, most researchers and practitioners still considered it in their study [13], [14].

The purpose of the present study is to validate two model approaches of the individual (crest-to-trough) wave heights distribution against wave measurement data obtained from laboratory-generated. Probabilistic models applied in the estimation of the wave heights distribution are the Rayleigh distribution and the Weibull distribution adopted by Forristal, 1978 [10]. Some researchers have used the Weibull distribution model to estimate the statistical distribution of random waves, which are suggested as the short-term model for wave heights in the paper [4], [6], [11], [15], [16],[17]. To this end, laboratory experiments of a generated random wave with primary spectral parameters of significant wave height and wave peak period were conducted in the ocean basin.

\section{Methods}

The measurement of random wave time series data is carried out at Indonesian Hydrodynamics Laboratory, Center for Hydrodynamics Technology, Agency for the Assessment and Application of Technology (BPPT). The laboratory of Maneuvering Ocean \& Basin (MOB) size for deep parts $60 \mathrm{~m}$ x $35 \mathrm{~m}$ x $2.5 \mathrm{~m}$ and shallow parts $45 \mathrm{~m}$ x $35 \mathrm{~m} \times 1.25 \mathrm{~m}$ (Figure 1 ). The wave generator can generate both regular and irregular wave heights, both long and short peak periods. A passive wave absorber in front of the wave generator is used to absorb the incident waves' energy. Random waves are generated by entering the wave spectrum parameters to the wave basin's control computer, then sending a motion signal to the wave generator. Measurements of the random wave surface elevation were conducted by one a wave probe tool (gauge) placed in front of the wave generator with a distance of $10 \mathrm{~m}$. The laboratory experiment was run with a model length scale of $1: 25$. Petrova \& Guedes Soares [18], [19] conducted the study of the distribution of wave heights from laboratory-generated sea states.

In this study, random wave heights were generated under four sea states, as shown in Table 1 . Each sea states are represented by only one wave parameter of significant wave height and peak period. This simulation does not describe the total range of significant wave heights and peak periods in each sea state and not applicable to any single sea state's general case. The range of significant wave heights in sea states is in reference [20]. The generated random waves in the ocean basin are represented by ocean waves' characteristics based on wave spectrum models.

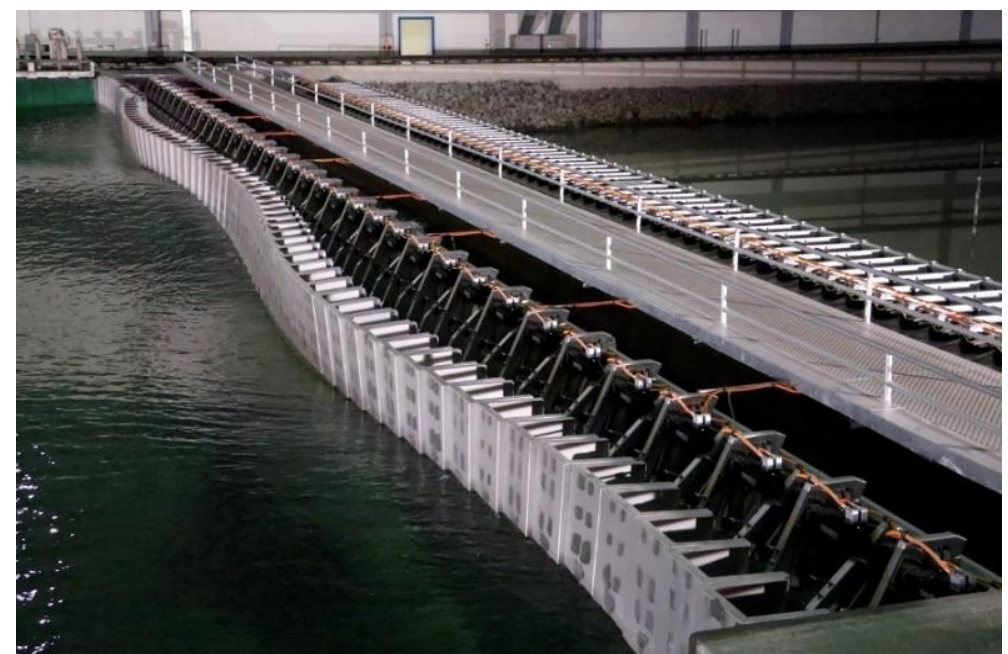

Figure 1. Wave Generator Developed by Bosch Rexroth at Indonesian Hydrodynamics Laboratory

Table 1. The Wave Parameters In Sea State

\begin{tabular}{lll}
\hline Wave conditions & Hs $(\mathbf{m})$ & Tp $(\mathbf{s})$ \\
\hline Sea state 3 & 1.10 & 4.00 \\
Sea state 4 & 2.00 & 7.00 \\
Sea state 5 & 3.85 & 9.00 \\
Sea state 6 & 5.75 & 13.00 \\
\hline
\end{tabular}

\subsection{Wave Spectrum}

The ocean wave spectrum has one or more peak energy magnitude. The peak spectrum can describe the characteristics of sea state wave energy. The power spectral density can be determined by the parametric model of the sea state design. The form of spectrum area that is commonly used for engineering design is the Pierson-Moskowitz spectrum model with the following equation [21]:

$$
S_{P M}=0.11087 \frac{H_{s}{ }^{2}}{T_{z}{ }^{4}} f^{-5} \exp \left[-0.44336 \frac{f^{-4}}{{T_{z}}^{4}}\right]
$$

where $H_{s}$ is a significant wave height, $T_{z}$ is the wave peak period, and $f$ is wave frequency. 
[21]:

Whereas the shape of the JONSWAP spectrum model has a more complex form, the equation can be written as follows

$$
S_{J}=\alpha \frac{g^{2}}{(2 \pi)^{5}} f^{-5} \exp \left[-\frac{5}{4}\left(\frac{f}{f_{p}}\right)^{-4}\right] \gamma^{\exp \left(-\frac{\left(1-\frac{f}{f_{p}}\right)^{2}}{2 \sigma^{2}}\right)}
$$

where $\alpha$ is the spectral energy parameter, $f_{p}$ is the spectral peak frequency of the JONSWAP spectrum, $\gamma$ is the peak enhancement factor, $\sigma$ is the spectral width parameters, and $\sigma$ can be determined by

$$
\sigma=\left\{\begin{array}{l}
0.07 \text { for } f \leq f_{p} \\
0.09 \text { for } f>f_{p}
\end{array}\right.
$$

The generated random ocean waves in laboratory experiments were modeled using the Pierson-Moskowitz and Jonswap spectrum. The Pierson-Moskowitz spectrum model for wave conditions of sea state 3 and 4 . Meanwhile, the Jonswap spectrum model was used for random wave conditions of sea state 5 and 6 because they are the considerable wave heights. The Jonswap spectra formulation is a modification of the Pierson-Moskowitz, which the input consideration of parameters that represent the characteristics of closed water waves or islands. The Jonswap spectrum model is often used to analyze Indonesia's offshore design because Indonesia's state waters are closed water waves or archipelagic waters [22].

\subsection{Fourier Transform Analysis}

The mathematical form of ocean wave characteristics shown in the recording of random signals or periodic system vibrations can be converted into the wave spectrum. The data of random wave motion can be represented by the Fourier series, which contains periodic components of basic frequencies that generate a random wave. The random wave elevation can be written in the form of an equation as follows [22]:

$$
\xi(t)=\bar{\xi}+\sum_{n=1}^{N} A_{n} \cos \left(\omega_{n} t\right)+B_{n} \sin \left(\omega_{n} t\right)
$$

where the frequency component, the coefficients $A_{n}$ and $B_{n}$ can be calculated with the following equation:

$$
\omega_{n}=\frac{2 \pi n}{T_{H}}(\mathrm{rad} / \mathrm{det})
$$

for $\mathrm{n}=1,2,3 \ldots$ and so on.

$$
\begin{aligned}
& A_{n}=\frac{2 \pi}{T_{H}} \int_{0}^{H} \xi(t) \cos \left(\omega_{n} t\right) d t \\
& B_{n}=\frac{2 \pi}{T_{H}} \int_{0}^{H} \xi(t) \sin \left(\omega_{n} t\right) d t
\end{aligned}
$$

The equation above shows that irregular or random waves are a function of a combination of regular waves in large numbers that can be infinite.

\subsection{Probability Distribution Models of Wave Height}

The estimation model for the wave heights distribution is based on the probability distribution of occurrence. The proper representation of maximum ocean waves in a sea state is required in the design, as predicting wave amplitude cannot be neglected. Moreover, the nonlinear impact must be carried out into calculation. In general, the probability distribution of wave heights using models is mostly applied in engineering by practitioners and researchers. The Rayleigh and Weibull distribution models have been selected for comparison with the measured data from laboratory experiments. Although the theory of knowledge about probability distribution has been developed rapidly, some practitioners still consider these models for predicting the statistical distribution of the random wave. Mackay [23] presented the Rayleigh distribution with sufficient bandwidth parameters accurately for the ocean wave distribution. Some authors have suggested that wave heights fit more adequately with other probability laws, such as the Weibull distribution [11].

The probability distribution of wave heights using the Rayleigh distribution can be predicted using the following equation [8] :

$$
P\{H\}=\exp \left\{-\left(\frac{H}{8 \sigma_{\eta}^{2}}\right)^{2}\right\}
$$


where $P\{H\}$ is the probability of occurrence of an individual wave height $(H)$, then $\sigma_{\eta}$ is the standard deviation of the free surface elevation in the sea state. Although the Rayleigh model is included in the deep-water model category. However, the Rayleigh model is considerably applied in all water depths.

While the Weibull distribution adopted by Forristall [10] is the exponential distribution. It is also often used for estimating the wave heights distribution. The probability of exceedance define by the Forristall model is given by:

$$
P\{H\}=\exp \left\{-\frac{1}{\beta}\left(\frac{H}{\sigma_{\eta}}\right)^{\alpha}\right\}
$$

where $\alpha=2.126$ and $\beta=8.42$ which are obtained by using some procedure in fitting empirical data. This distribution has been mostly adopted in both intermediate and deep waters. The Forristall model is a Weibull distribution calibrated using the field measurement data recorded during hurricanes in the Gulf of Mexico, and this model achieved a good agreement between the Weibull distribution.

\section{Results and Discussion}

The experimental data in laboratory measurements at deep parts basin have been conducted at least 30 minutes at fullscale for each sea state. The sampling rate of random wave measurement was set at $50 \mathrm{~Hz}$ for a gauge. The determination of recorded wave heights in each sea state has lasted approximately 300 - 400 zero-up-crossing waves for stable statistical properties. The number of measured wave data in each sea state is at least 100 pairs of crest and trough waves. This procedure was conducted to obtain reliable statistical data information [24]. At least 100-200 waves have traditionally been used, which is often defined as acceptable if linear effects only are considered [25]. The measurement sample of time series wave data can be seen in Figure 2.
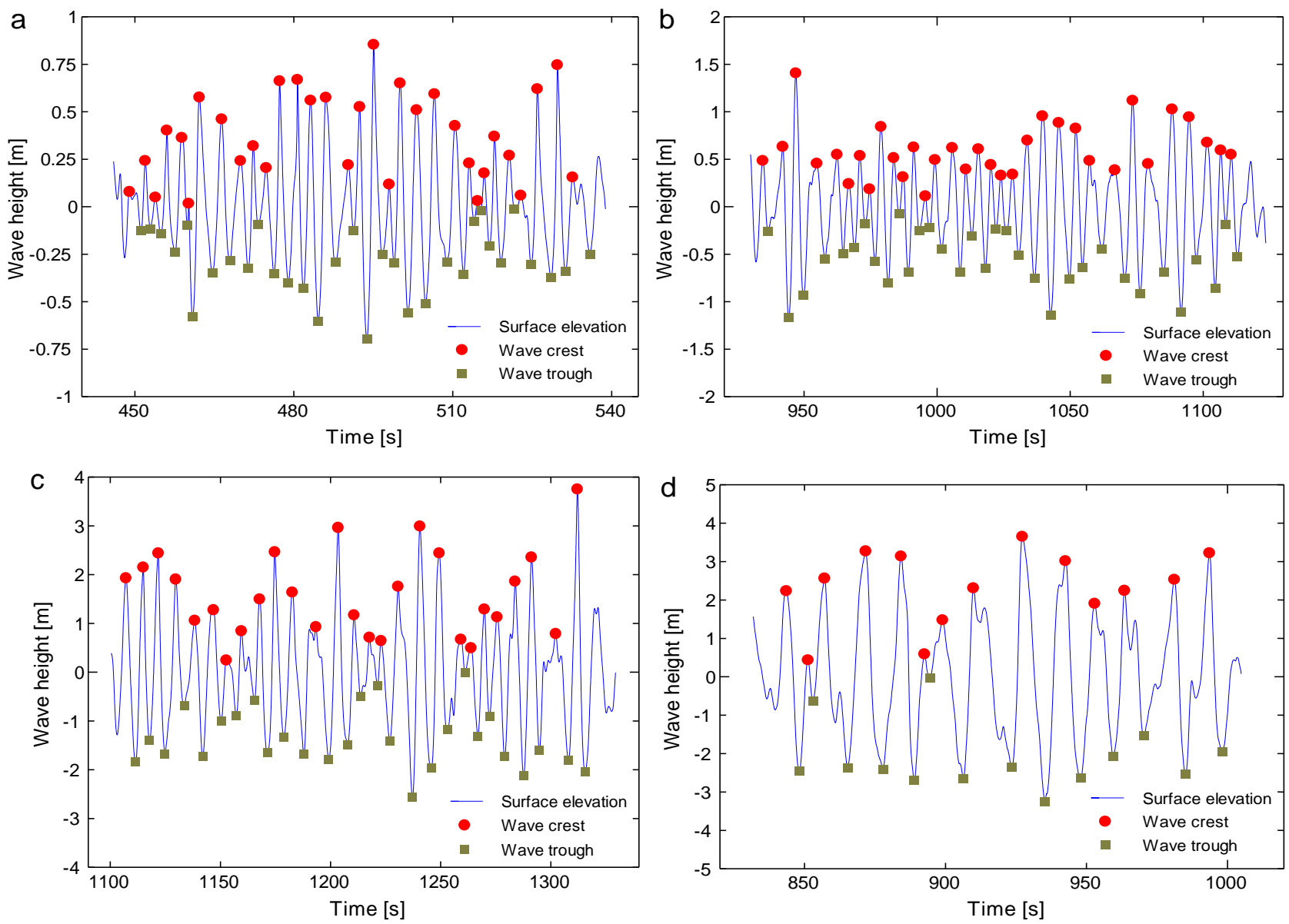

Figure 2. The Sample of Measured Time Series of Wave Elevation for Sea State 3 (a), Sea State 4 (b), Sea State 5 (c), And Sea State $6(d)$.

The random wave time series data in this study was carried out by direct measurement of the wave surface elevation at the Laboratory of the ocean basin. A statistical analysis of measured wave data was performed using open-source software such as Octave for time-domain analysis and frequency domain analysis of a wave record. The statistical result of the random wave time series in each sea states was obtained by averaging the up and down crossing, including individual wave heights, wave crests, wave trough and standard deviation 


\subsection{Spectra Analysis of Ocean Basin}

The characteristics of measured random waves in the ocean basin can be presented in the wave energy spectrum. With an analysis method of the fast Fourier transform, random waves are expressed in one individual wave's total energy. Spectral analysis is performed using this method for converting data from a time domain to a frequency domain. The decomposition of regular wave energy with a certain period is collected into one broad spectrum of wave energy, which can be called a sea state wave spectrum.

A study of ocean wave data conversion into the wave spectrum was carried out with the Fourier transforms analysis process [26]. The conversion result of random wave time series data into a wave spectrum, both measurement data and theoretical, can be seen in Figures 3 and 4. The statistical results of the measured wave spectrum are used to validate the random wave generated in an ocean basin.
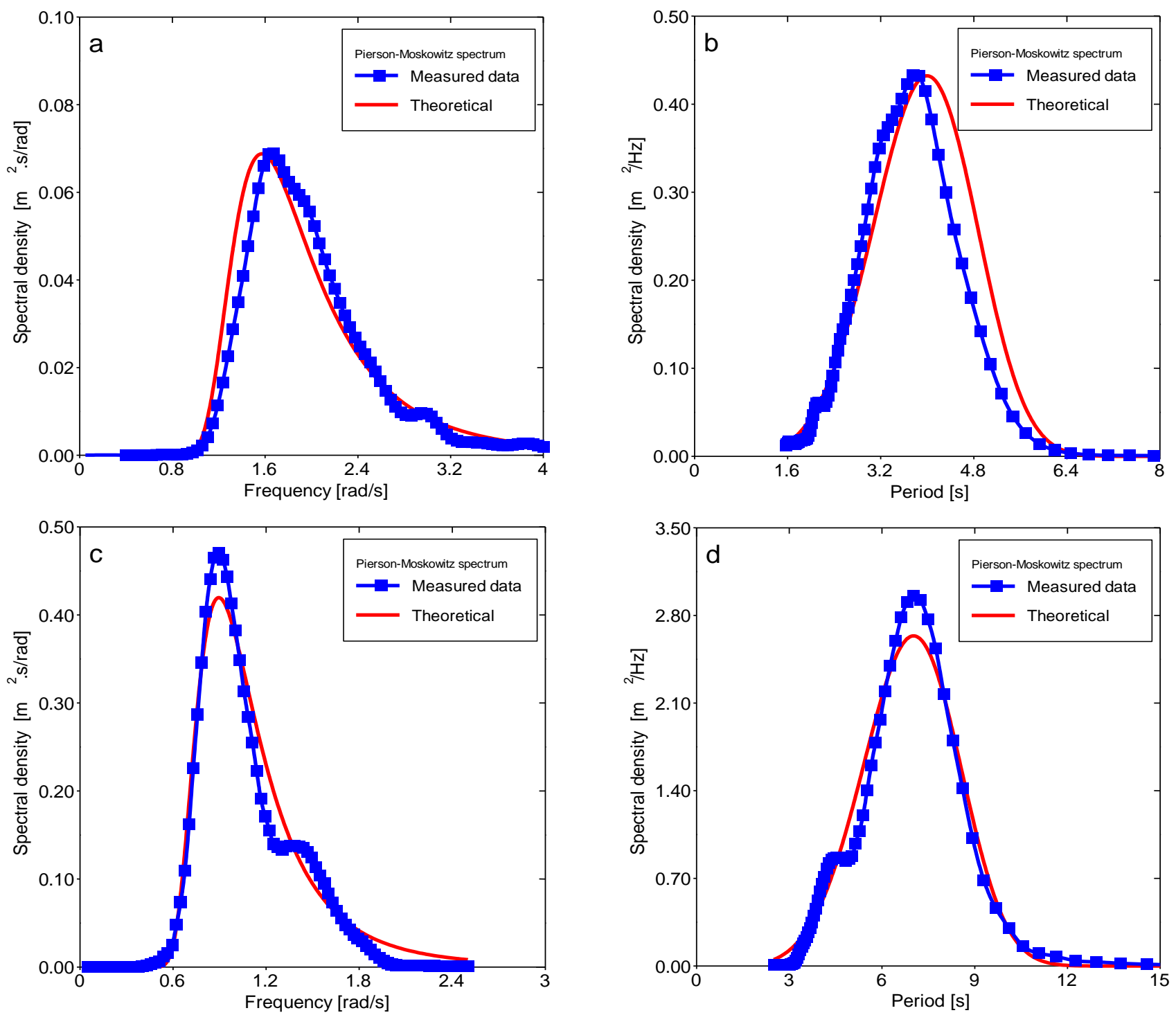

Figure 3. Comparison of the Wave Spectrum Between the Measured Experimental Data And the Pierson-Moskowitz Spectrum, for Sea State 3 (a) and (b); Sea State 4 (c) and (d).

The spectral approximated of significant wave height can be counted from the spectral moment of zeroth order $m_{0}$ as the following equation:

$$
H_{s}=4 \sqrt{m_{0}}
$$

Various wave characteristics can be assessed from one-dimensional sea surface variance density of wave frequencies $S(f)$. The total wave energy spectrum is represented as a function of frequency $(f)$. The spectral moment of $n$-th order $\left(m_{n}\right)$ for the non-directional of spectral density is calculated using the following equations :

$$
m_{n}=\sum_{i=1}^{n} f_{i}^{n} S(f) \Delta f
$$



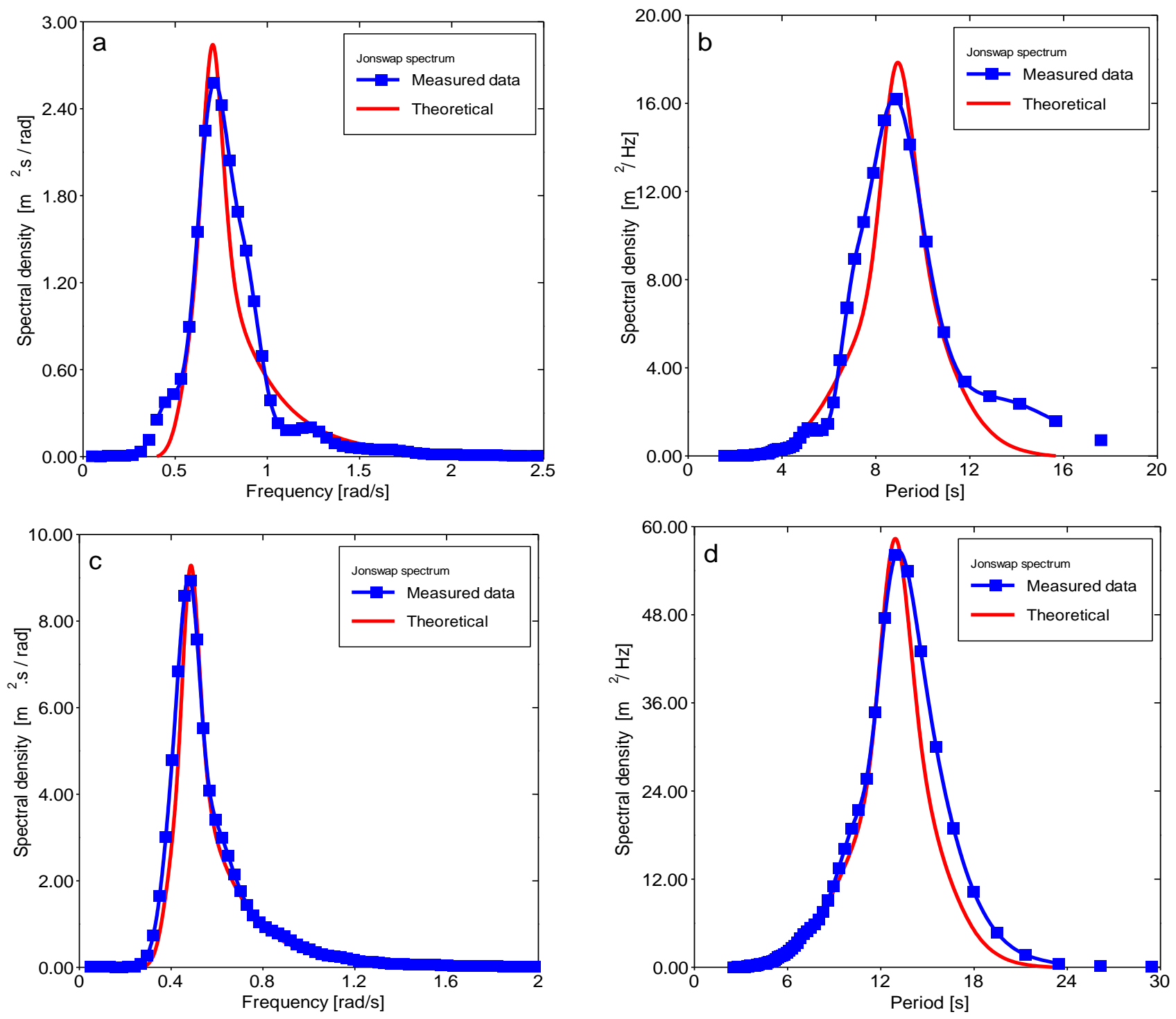

Figure 4. Comparison of the Wave Spectrum Between the Measured Experimental Data And The Jonswap Spectrum, for Sea State 5 (a) and (b); Sea State 6 (c) and (d)

The wave spectrum of sea state conditions 3 and 4 are shown in Figure 3. The analysis of the measured wave spectrum compared with the Pierson-Moskowitz theoretical spectrum. For wave condition of sea state 3 , the measured spectrum shows similarity to the theoretical spectrum (Figure 3a and 3b), although the peak energy of spectral density shifts slightly. The measured spectrum at wave condition of sea state 3 indicates similarity to the theory in high frequencies.

Using Eq. 10, the significant wave height of the spectral density obtained a value of $1.06 \mathrm{~m}$. For sea state 4 , the wave spectrum's shape is generally almost the same as the theoretical spectrum (Figure $3 \mathrm{c}$ and $3 \mathrm{~d}$ ). The peak energy of the measured spectrum was slightly high to the theory and showed two peaks slightly. The measured wave spectrum of sea state 4 shows more similarity to the theoretical spectrum at low frequencies. The significant wave height of sea state 4 in spectral density obtained the value of $1.98 \mathrm{~m}$.

Subsequently, the individual components have been modeled by a non-directional Jonswap spectrum with peak enhancement factor $g=2.5$ to generate an ocean wave basin for sea state 5 and 6 . Figure 4 compares the measured and the theoretical spectral density for sea state 5 and 6 . In the wave spectrum of sea state 5 , the spectral calculation result shows a good match with the theoretical spectral at low frequencies and peak frequency, as shown in Figures 4a and 4b. However, the measured spectrum wave's peak energy is slightly lower than the Jonswap spectrum theory.

The statistical calculation of significant wave height from the spectral density is a value of $3.83 \mathrm{~m}$. A similar characteristic was observed to compare the wave spectrum in sea state 6 (Figure $4 \mathrm{c}$ and $4 \mathrm{~d}$ ). The measured spectrum analysis results in wave condition of sea state 6 indicate a good match in most frequencies. A significant wave height of $5.82 \mathrm{~m}$ was obtained from statistical spectral density calculation.

The measurement results of the validated wave spectrum analysis can be seen in Table 2. The comparison of results between experimental and theoretical wave parameters usually depends on the user's results, the tolerance for significant wave heights is $5 \%$ and the peak wave period is $2 \%$. The required tolerances in the wave parameter's laboratory measurements are usually $\pm 5 \%$ for both significant wave height and peak wave period [25].

Even though the spectral density area's position is shifted, the area magnitude is almost the same. The data of primary spectral parameters based on the wave spectrum can be used to design the sea structure affected by the wave excitation 
force. For the case of wave energy converter design, the designer can estimate the converter performance's operability to work at the used energy level.

Table 2. The Validation of Wave Parameters in Sea State

\begin{tabular}{lllll}
\hline Wave conditions & \multicolumn{2}{l}{ Theoretical } & \multicolumn{2}{l}{ Measured } \\
\cline { 2 - 5 } & Hs $(\mathbf{m})$ & Tp $(\mathbf{s})$ & Hs $(\mathbf{m})$ & Tp $(\mathbf{s})$ \\
\hline Sea State 3 & 1.10 & 4.00 & 1.06 & 3.90 \\
Sea State 4 & 2.00 & 7.00 & 1.98 & 7.03 \\
Sea State 5 & 3.85 & 9.00 & 3.83 & 8.87 \\
Sea State 6 & 5.75 & 13.00 & 5.82 & 12.94 \\
\hline
\end{tabular}

\subsection{Approximations of Wave Distribution}

Applying an individual wave height distribution model for definite sea state conditions is essential for practical purposes. In this section, the observed probabilistic distribution of ocean wave heights is discussed and compared with Rayleigh and Weibull model. The study of a predicted probability distribution of wave crest height using the Rayleigh and Weibull distribution [14]. The statistical distribution of the sea wave height has been modeled using the Rayleigh and Weibull distribution [6], [17]. This prediction uses a linear probability model intended to expect the occurrence of individual wave height in general. The theoretical model and numerical simulations method can be utilized to count the exceedance probabilities of ocean wave heights based on a specific spectrum [27]. The comparison of exceedance probabilities between the estimation models applicable to wave heights and the laboratory experiment data are shown in Figure 5. The black squares denote the observation data, representing the wave heights distribution's statistical result based on the measured experimental. The solid blue line indicates the Rayleigh model, and the solid red line indicates the Weibull model. The black squares are used as a benchmark against the accuracy of the prediction model for the wave heights distribution.
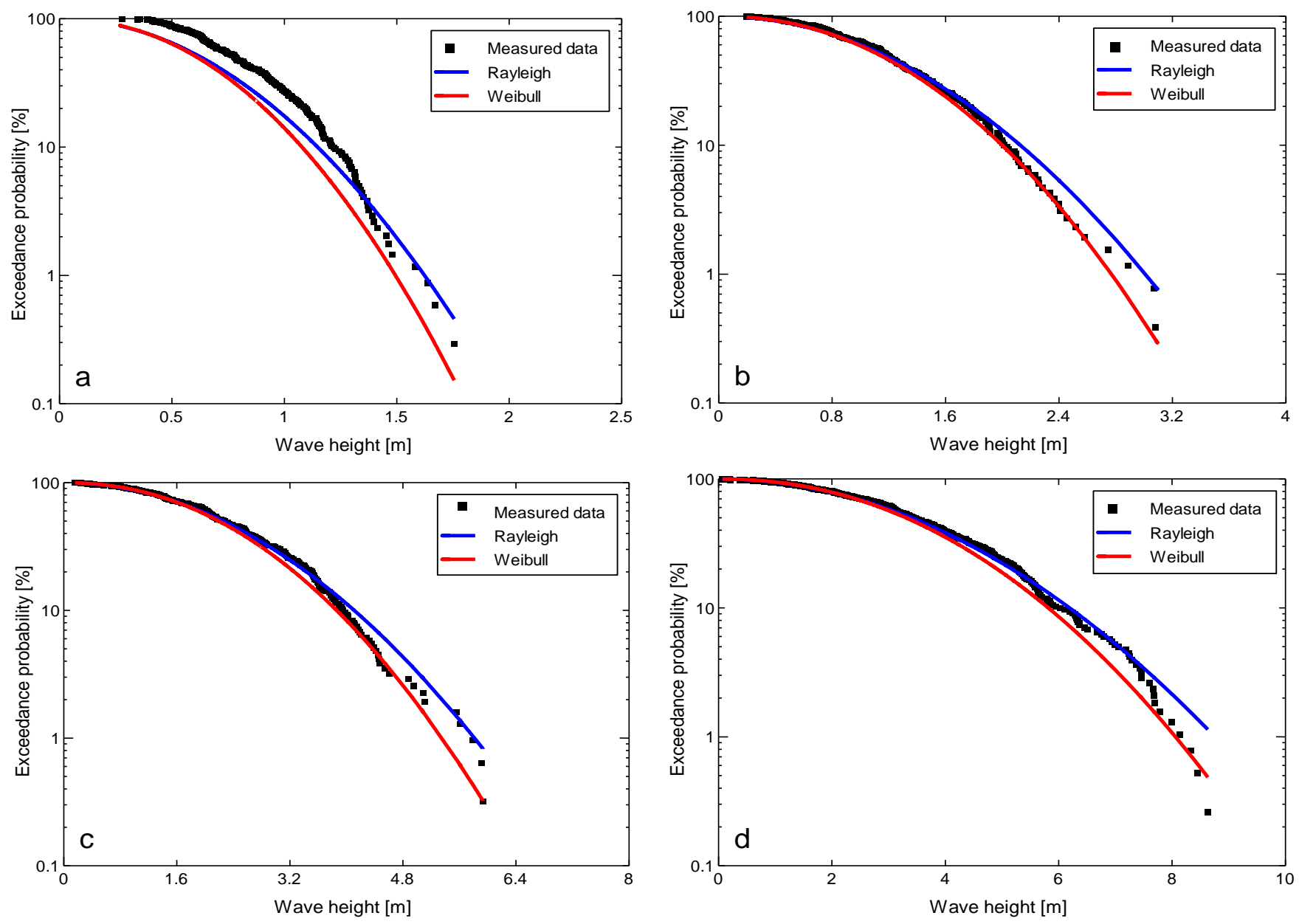

Figure 5. Comparison of Exceedance Probability of Wave Heights Between Rayleigh Distribution, Weibull Distribution and the Measured Experimental Data, for Various Sea States : (a) sea state 3; (b) sea state 4; (c) sea state 5; (d) sea state 6.

In Figure 5a for the exceedance probability of sea state 3, we can find out that predicting wave heights probabilities distribution for both Rayleigh and Weibull models deviate from the distribution of the measured experimental data. The Rayleigh model shows to underestimate the small and intermediate wave height. After that, the prediction is seen to slightly overestimates. 
While the Weibull model, the prediction is seen to underestimate for all wave height segments. The prediction model of wave height probability distribution in sea state 4 can be seen in Figure 5b. It is seen that exceedance probability obtained from using a Weibull model provide a good agreement with the corresponding benchmark result based on measured data of wave heights. Moreover, the Rayleigh model shows the best description for the small wave height, but the curve consistently overestimates for more considerable wave height.

The comparison results of the wave height probability distribution show a good similarity between the measured data and the Weibull model in sea state 5 . The exceedance probability of sea state 5 can be seen in Figure $5 c$. The Rayleigh model provides a fitting well the small wave heights to slightly overestimates the intermediate and large data.

Figure $5 d$ shows the prediction result of wave height exceedance probabilities of sea state 6 . Rayleigh's distribution result indicates a similarity with the measured data, but the prediction is slightly overestimated for a large range of wave heights. In the Weibull model, the predictions tend to be similar to the data. However, the intermediate wave is seen to overestimate. In some cases, the distribution of measured data shows a nonlinear phenomenon for the largest wave height.

The distribution models of Rayleigh and Weibull are a linear model, while the measured experimental wave elevation series is nonlinear. The prediction of both Rayleigh and Weibull models has been applied using the laboratory measurement data to show the wave data characteristics in each sea state. The distribution model results show the similarity from low to large wave height. However, coinciding or similarity can also be preceded, then the prediction of the intermediate wave height is far from each other.

The prediction can also create a slightly cross graph in wave condition of sea state 3, which can be seen in Figure 5 a. Wang investigated the results of predicted wave crest height probability with the Rayleigh model and other models show unequal results for sea state conditions due to nonlinear waves or the spectral bandwidth effect [27]. The prediction of wave height component distribution using Rayleigh, Ochii, and Mori \& Yasuda models shows the close together and away from the data due to the nonlinear effect [5]. Karmpadakis et al. [7] investigated the comparison of wave height distributions between nine widely applied theoretical and field measurements have shown that no single model can describe the measured wave data across a wide condition accurately.

\section{Conclusion}

The values of significant wave height and peak wave periods from the measured time series are calculated based on a statistical analysis of frequency domains. The measured wave spectrum is validated with a theoretical wave spectrum for generating wave-free surface elevation time series in the ocean basin. A good match is observed between the measurement and theoretical models. The tolerance for both significant wave height and peak period is still below $5 \%$.

This study has presented an analysis of the wave heights distribution of laboratory measurements using a widely applied wave height model. This study's focus is predicting wave height distribution, as described by the Rayleigh and Weibull model. The Weibull model shows better results than the Rayleigh model for sea state 4 and 5 . The Rayleigh model gives the best fit to the data over the intermediate range for sea state 6 .

The Rayleigh model provides to overpredict the observations systematically at the extreme tail of the distributions. In the case of sea state 3, both models show not good results. Each prediction model has advantages depending on the condition of the sample wave height data. So, the appropriateness of the commonly applied models is critically dependent upon sea state conditions. The prediction results of the distribution model that deviate due to the effects of the distribution of nonlinear sample data.

\section{Acknowledgements}

The corresponding author would like to thank the Ministry of Research and Technology of the Republic of Indonesia for providing financial support through the Saintek Scholarship in 2019-2021. The author also thanks the Indonesian Hydrodynamic Laboratory - BPPT for the wave height measurement data carried out in the Maneuvering Ocean and Basin (MOB) unit.

\section{References}

[1] T. Thevasiyani and K. Perera, "Statistical analysis of extreme ocean waves in Galle, Sri Lanka," Weather and Climate Extremes, vol. 5, pp. 40-47, 2014.

[2] J. Zhang, M. Benoit, O. Kimmoun, A. Chabchoub, and H.-C. Hsu, "Statistics of extreme waves in coastal waters: large scale experiments and advanced numerical simulations," Fluids, vol. 4, no. 2, p. 99, 2019.

[3] M. Prevosto, H. E. Krogstad, and A. Robin, "Probability distributions for maximum wave and crest heights," Coastal Engineering, vol. 40, no. 4, pp. 329-360, 2000.

[4] C. G. Soares and R. Pascoal, "Experimental Study of the Probability Distributions of Green Water on the Bow of Floating Production Platforms," Journal of Offshore Mechanics and Arctic Engineering, vol. 127, no. 3, pp. $234-242,2004$.

[5] Z. Cherneva, P. Petrova, N. Andreeva, and C. G. Soares, "Probability distributions of peaks, troughs and heights of wind waves measured in the black sea coastal zone," Coastal Engineering, vol. 52, no. 7, pp. 599-615, 2005.

[6] T. Q. Tuan and D. Q. Cuong, "Distribution of wave heights on steep submerged reefs," Ocean Engineering, vol. 189, p. 106409, 2019.

[7] I. Karmpadakis, C. Swan, and M. Christou, "Assessment of wave height distributions using an extensive field database," Coastal Engineering, vol. 157, p. 103630, 2020.

[8] M. S. Longuet-Higgins, "On the statistical distribution of the height of sea waves," JMR, vol. 11, pp. 245-266, 1952. 
[9] C. Li, D. Yu, and Y. Gao, "Crest-height distribution of nonlinear random waves," Journal of Ocean University of China, vol. 9, pp. 31-36, 2010.

[10] G. Z. Forristall, "On the statistical distribution of wave heights in a storm," Journal of Geophysical Research: Oceans, vol. 83, no. C5, pp. 2353-2358, 1978.

[11] C. Guedes Soares and A. N. Carvalho, "Probability Distributions of Wave Heights and Periods in Measured Combined Sea-States from the Portuguese Coast," Journal of Offshore Mechanics and Arctic Engineering, vol. 125, no. 3, pp. 198204, 2003.

[12] M. A. Tayfun and F. Fedele, "Wave-height distributions and nonlinear effects," Ocean engineering, vol. 34, no. 11-12, pp. 1631-1649, 2007.

[13] Y. Wang, "Transformed Rayleigh distribution of trough depths for stochastic ocean waves," Coastal Engineering, vol. 133, pp. 106-112, 2018.

[14] V.S. Kumar, S. Harikrishnan, and S. Mandal, "Wave crest height distribution during the tropical cyclone period," Ocean Engineering, vol. 197, p. 106899, 2020.

[15] J. A. Battjes and H. W. Groenendijk, "Wave height distributions on shallow foreshores," Coastal engineering, vol. 40, no. 3, pp. 161-182, 2000.

[16] V. Katsardi and C. Swan, "An experimental study of shallow water wave statistics on mild bed slopes," in International Conference on Offshore Mechanics and Arctic Engineering, 2011, vol. 44342, pp. 711-719.

[17] Y. Wu, D. Randell, M. Christou, K. Ewans, and P. Jonathan, "On the distribution of wave height in shallow water," Coastal Engineering, vol. 111, pp. 39-49, 2016.

[18] P. G. Petrova and C. G. Soares, "Probability distributions of wave heights in bimodal seas in an offshore basin," Applied Ocean Research, vol. 31, no. 2, pp. 90-100, 2009.

[19] P. G. Petrova and C. G. Soares, "Wave height distributions in bimodal sea states from offshore basins," Ocean engineering, vol. 38, no. 4, pp. 658-672, 2011.

[20] I. F. Glen, R. B. Paterson, and L. Luznik, "Sea operational profiles for structural reliability assessment, Ship Structure Committee, Report No," SSC-406, Washington, DC, 1999.

[21] M. Olagnon, K. Ewans, G. Forristall, and M. Prevosto, "West Africa Swell Spectral Shapes," 2013, vol. Volume 2B: Structures, Safety and Reliability.

[22] E. B. Djatmiko, "Perilaku dan Operabilitas Bangunan Laut di Atas Gelombang Acak," ITS-Press. Surabaya. Inonesia, 2012.

[23] E. B. L. Mackay, "8.03 - Resource Assessment for Wave Energy," in Comprehensive Renewable Energy, A. Sayigh, Ed. Oxford: Elsevier, 2012, pp. 11-77.

[24] J. M. J. Journée and J. A. Pinkster, "Offshore hydromechanics," TUDelft, Faculty of Marine Technology, Ship Hydromechanics Laboratory, Report No. 1112-K, Lecture Notes, 1997.

[25] ITTC, "Laboratory Modelling of Waves: regular, irregular and extreme events," in ITTC-Recommended Procedure and Guidelines, 2017, pp. 1-12.

[26] R. M. Gorman, "Estimation of directional spectra from wave buoys for model validation," Procedia Iutam, vol. 26, pp. 81-91, 2018.

[27] Y. Wang, "Predicting absorbed power of a wave energy converter in a nonlinear mixed sea," Renewable Energy, vol. 153, pp. 362-374, 2020. 